\title{
Hidrolojik Parametrelerin Pik Debi Üzerindeki Duyarlılıklarının İncelenmesi
}

\author{
Hüseyin AKAY ${ }^{*}$ \\ ${ }^{1}$ İnşaat Mühendisliği Bölümü, Mühendislik Fakültesi, Gazi Üniversitesi, Ankara, Türkiye \\ *11hakay@gazi.edu.tr
}

(Geliş/Received: 12/10/2019;

Kabul/Accepted: 07/02/2020)

\begin{abstract}
Öz: Bu çalı̧̧manın amacı hidrolojik parametrelerin pik debi üzerindeki duyarlılıklarının incelenmesidir. Bunun için Batı Karadeniz Havzası'nda yer alan ve akım ölçümleri bulunmayan Akçay Havzası'nın ArcGIS ve HECGeo-HMS yazılımları kullanılarak havza modeli oluşturulmuştur. Havzaya ait zemin tipi ve arazi kullanım haritaları kullanılarak havzanın eğri numarası tahmin edilmiştir. Havzanın karakteristikleri de dikkate alınarak toplanma süresi ve depolama katsayısı tahmin edilmiş ve HEC-HMS yarı dağılımlı hidrolojik modeli kullanılarak dolaysız akış hesaplanmıştır. Tahmin edilen hidrolojik parametreler belirsizlik içerdiğinden hidrolojik parametreler üniform, normal ve üçgen istatistiksel dağılımları dikkate alınarak ve eşit değişim katsayısı kullanılarak Monte Carlo yaklaşımıyla 10000 adet üretilmiştir. Bu parametrelerle pik debiler hesaplanmış, güven aralıkları belirlenmiş ve lokal duyarlılık analizleri yapılmıştır. İstatistiksel dağılımdan bağımsız olarak eğri numarası pik debi üzerinde en büyük duyarlılığa sahip olurken toplanma süresinin pik debi üzerinde en az duyarlılığa sahip olduğu görülmüştür. Ayrıca dolaysız akış parametrelerinden depolama katsayısının toplanma süresine kıyasla pik debi üzerinde daha fazla duyarlılığa sahip olduğu anlaşılmıştır.
\end{abstract}

Anahtar kelimeler: Batı Karadeniz Havzası, duyarlılık analizi, HEC-HMS hidrolojik modeli, Monte Carlo analizi.

\section{Investigation of Sensitivity of Hydrologic Parameters on Peak Discharge}

\begin{abstract}
The aim of this study is to investigate the sensitivity of hydrologic parameters on peak discharge. The basin model of Akçay Basin which is ungauged and located in the Western Black Sea Basin was created by using ArcGIS and HECGeoHMS softwares. Using the soil type and land use maps of the basin, the curve number of the basin was estimated. Time of concentration and storage coefficient of the basin were estimated taking into consideration the characteristics of the basin and the direct runoff was calculated using the HEC-HMS, semi-distributed hydrological model. Since the predicted hydrological parameters contain uncertainty, 10000 numbers of parameters were produced by using Monte Carlo approach by taking uniform, normal and triangular statistical distributions into consideration and using equal coefficient of variation. Peak flow rates were calculated with these parameters, confidence intervals were determined and local sensitivity analyses were performed. Regardless of the statistical distribution, the curve number has the most sensitivity, while the time of concentration has the least sensitivity on the peak discharge. It was also noted that the storage coefficient of the basin which was efficient in transformation of effective precipitation to direct runoff had more sensitivity on the peak flow than the time of concentration.
\end{abstract}

Key words: Western Black Sea Basin, Sensitivity analysis, HEC-HMS hydrological model, Monte Carlo analysis.

\section{Giriș}

Bir havzada yağış-akış ilişkisinin tahmininde hidrolojik süreçlerde kullanılan parametreleri tahmin etmek ve bu parametrelerin sonuçlar üzerindeki etkisini belirlemek uzun yıllardır devam edegelen araştırma konularından biridir. Arazi deneyleri, gözlemlerle desteklenmiş uzaktan algılama yöntemleri, bilinen yağış̧-akış ilişsisine göre hidrolojik parametrelerin kalibrasyonu gibi yöntemler yaygın olarak kullanılmakta ve daha hassas ve ekonomik sonuçların elde edilmesi için çalışmalar devam etmektedir [1-3]. Havzaların drenaj alanı, en uzun akım yolu, havzanın eğimi, Benson eğimi gibi havza büyüklükleri ile hidrolojik parametreler arasında çok iyi belirleme katsayısına $\left(\mathrm{R}^{2}\right)$ sahip regresyon analizleri yapılarak tahmin edilen hidrolojik parametrelerin akışı makul seviyede tahmin ettiği görülmüştür [4-7]. Hidrolojik parametreleri tahmin etmek için yapılan kabuller ve basitleştirmeler gerçekte bu parametrelerin doğada rastgele dağılım göstermesinden ve bazı sınırlamaları kabul etmemesinden ötürü belirsizliklere neden olabilmektedir [8]. Tahmin edilen hidrolojik parametrelerin belirsizliklerinin incelenerek sonuçlar üzerindeki etkileri ve anlamlılık düzeyleri değerlendirilmelidir. Parametre

\footnotetext{
* Sorumlu yazar: hakay@gazi.edu.tr. Yazarların ORCID Numarası: ${ }^{1}$ 0000-0002-9714-4590
} 
belirsizliklerine göre hesaplanan sonuçların güvenilirliği, istatistiksel anlamlılık düzeyi ve parametre sayısı temelinde hesaplanan güven aralığına göre karar verilmesine olanak sağlar.

Yağıştan akışa kadar geçen süreçlerde hidrolojik parametrelerin her birinin hassas olarak belirlenebilmesi oldukça güçtür. Yağış-akış ilişkisinin bünyesinde var olan hidrolojik süreçlerin iç içe geçmiş olması bu süreçlerdeki parametrelerin belirsizliğini de doğrudan etkileyebilmektedir. Her bir parametrenin taşıdığ belirsizlik, tahmin edilen ve doğrulanan akış sonuçlarında da önemli ölçüde değişimlere/sapmalara neden olabilmektedir. Duyarlılık analizi, model sonuçlarında oluşan belirsizliğe neden olan parametreyi belirlemeye yardımcı olur. Yağış-akış sürecinde kullanılan yöntem parametrelerinin tahmin edilen sonuçlar üzerindeki baskınlıklarının bilinmesi farklı firtınalarda yapılan doğrulama sonuçlarının da belirsizliği ya da hassaslığı hakkında fikir verebilmektedir. Tahmin edilen hidrolojik parametrelerin istatistiksel davranışlarının veya eğilimlerinin bilinmesi parametrelerin tahmin edilen sonuçlar üzerindeki duyarlılığının da belirlenmesine yardımcı olabilmektedir. Duyarlılık analizi, tahmin sonuçlarına en duyarlı parametrenin belirlenmesine ve duyarlılığı az olan parametrenin kalibrasyon sürecinden çıkarılarak gereksiz işlemden kaçınılmasına imkan sağlamaktadır [8].

Tahmin edilen hidrolojik parametrelerin belirsizliği ve tahmin sonuçlarını ne ölçüde etkilediği ya da aynı sonuçların parametrelerin farklı değerlerine göre de elde edilebileceği, parametrelerin benzersiz olmaması problemine yol açabilmektedir. Kalibre edilen parametrelerin benzersizliği sorununu aşmak için araştırmacılar çalışmalarında farklı optimizasyon tekniklerini kullanmışlardır. Belirsizlik konusunu önemseyen hidrolojik modellerde farklı algoritmalar kullanılarak detaylı belirsizlik/duyarlılık analizlerinin yapılabilmesi mümkün olabilmektedir. Birçok araştırmacı Soil \& Water Assessment Tool (SWAT) hidrolojik modelini kullanarak tahmin ettikleri hidrolojik parametrenin belirsizliklerini test etmişlerdir. Hatta araştırmacılar farklı optimizasyon algoritmalarını kullanarak tahmin edilen parametrelerin belirsizliğini karşılaştırmışlardır [8, 9]. HEC-HMS (Hydrologic Engineering Center - Hydrologic Modeling System) gibi bazı yarı dağılımlı hidrolojik modellerde bilinen yağış-akış ilişkisine göre hidrolojik süreçlerin tahmininde kullanılan parametreler çeşitli optimizasyon yöntemleri kullanılarak lokal düzeyde tahmin edilebilmektedir. Ayrıca, bazı araştırmacılar tahmin edilen parametrelerin sonuçlar üzerindeki duyarlılıklarını inceleyerek parametrelerin belirsizliği hakkında fikir sunmuşlardır [10-13]. Jamshid Mousavi ve diğerleri [11] SUFI 2 algoritmasını HEC-HMS modelinde kullanarak hidrolojik parametreleri belirsizlik temelinde kalibre etmişlerdir. Lehbab-Boukezzi ve diğerleri [13] çalıştıkları havzada GLUE yöntemini HEC-HMS modelinde kullanarak kalibre ettikleri parametrelerin belirsizliğini incelemişlerdir. Shamsudin ve diğerleri [10] hidrolojik süreçlerin modelinde kullanılan parametreleri kalibre ederek Monte Carlo yaklaşımıyla parametrelerin aralıklarını belirlemişlerdir. Araştırmacılar tarafından sunulan bu çalışmalarda belirsizlik konusu başarılı bir şekilde incelenmiş ve bazı öneriler sunulmuştur.

Kalibre edilen hidrolojik parametrelerin model sonuçları üzerindeki duyarlılıkları, kalibre edilen parametrelerin benzersizliğinin ve kalibrasyon tekniğinde kullanılan algoritmanın da bir başarı ölçütü olarak değerlendirilmektedir. Duyarlılık analizleri literatürde genellikle lokal ve global olmak üzere iki düzeyde yapılabilmektedir. Lokal olarak yapılan duyarlılık analizinde bir parametre değişirken diğer parametreler sabit bırakılarak parametre değişiminin elde edilen sonuçlar üzerindeki etkisi incelenmektedir. Lokal duyarlılık analizinde birkaç analizle parametrenin değişiminin sonuçlar üzerindeki etkisi anlaşılabilmektedir. Global duyarlılık analizinde ise tüm parametrelerin rastgele değer almasıyla parametrelerin değişiminin elde edilen sonuçlar üzerindeki etkileri de incelenebilmektedir. Global duyarlılık analizinde çok daha fazla sayıda analiz yapılarak parametrelerin değişiminin sonuçlar üzerindeki etkisi anlaşılabilmektedir [8].

Hidrolojik model sonucunda kalibre edilen hidrolojik parametrelerin farklı algoritmalar kullanılarak global duyarlılık analiz çalışmaları halen devam etmektedir. Linhoss ve diğerleri [14] iki farklı duyarlılık analiz sonuçlarını analiz yaptıkları hidrolojik modelde karşılaştırmışlar ve iklim değişikliği problemine karşı model ve duyarlılık analizi sonuçlarını havza gözlem çalışmalarına entegre etmişlerdir.

Bu çalışma kapsamında Batı Karadeniz Havzası'nda yer alan, sıklıkla taşkınlara maruz kalan ve akım ölçümleri bulunmayan Akçay Havzası'nın hidrolojik parametreleri, havza karakteristikleri kullanılarak tahmin edilmiş ve 2008 yılında meydana gelmiş yağış verileri kullanılarak HEC-HMS hidrolojik modeli yardımıyla modellenmiş ve dolaysız akış hidrografi tahmin edilmiştir. Hidrolojik süreçlerin modellenmesinde etkili olan parametreler, bazı olasılık yoğunluk fonksiyonları kullanılarak Monte Carlo yaklaşımıyla belirli sayıda rastgele parametre değerleri oluşturulmuştur. Bu parametreler hidrolojik modelde kullanılarak pik debiler hesaplanmış ve \%95 güven aralığında alt ve üst sınırdaki pik debiler belirlenmiştir. Ayrıca, hidrolojik parametrelerin pik debi üzerindeki lokal duyarlılıkları incelenerek parametrelerin pik debi üzerindeki duyarlılıkları en büyükten en küçüğe doğru sıralanmıştır. Böylelikle, bu çalışma ile hidrolojik parametrelerin tahmin edilmesinde meydana gelebilecek sapmanın tahmin edilen sonucu sayısal olarak ne ölçüde etkilediği hakkında fikir vermesi amaçlanmıştır. 


\section{Materyal ve Metod}

Çalışma kapsamında izlenen yöntem aşağıdaki gibi sıralanabilir.

a) Çalışma alanına ait 1/25000 ölçekli topoğrafik haritalar ArcGIS 10.1 yardımıyla sayısallaştırılarak Sayısal Yükseklik Modeli oluşturulur. ArcHydro araç çubuğu kullanılarak çalışma alanının arazi modeli oluşturulur.

b) Arazi modeli HECGeo-HMS'ye aktarılır ve havzanın karakteristikleri belirlenir.

c) Orman Bakanlı̆̆ı'ndan temin edilen arazi kullanım ve zemin tipi haritaları kullanılarak havzanın sızma modelinde ve toplanma süresinin hesabında kullanılan eğri numarası dağılımı belirlenir.

d) Akış parametreleri tahmin edilir.

e) Havza, hidrolojik analizinin yapılabilmesi için HEC-HMS'ye aktarılır ve Eylül 2008'de Çatalzeytin Meteoroloji Gözlem İstasyonu'nda gözlenen yağış verileri ve hesaplanan havza parametreleri kullanılarak dolaysız akış hidrografı ve pik debi hesaplanır.

f) Havzanın hidrolojik parametreleri Monte Carlo yaklaşımına göre farklı dağılımlar kullanılarak rastgele tahmin edilerek pik debi hesaplanır.

g) Hesaplanan pik debiler kullanılarak \%95 güven aralığında kalan pik debi aralıkları belirlenir.

h) Pik debiler üzerinde hidrolojik parametrelerin duyarlılığı hesaplanır.

\section{1. Çalışma alanı}

Bu çalışmada, $30000 \mathrm{~km}^{2}$ drenaj alanına, $811 \mathrm{~mm}$ yıllık ortalama yağışa ve $9.93 \mathrm{~km}^{3}$ yıllık akış hacmine sahip Batı Karadeniz Havzası'nda bulunan küçük bir alt havza çalışma alanı olarak seçilmiştir [15]. Akçay, Kastamonu Bozkurt ve Çatalzeytin ilçeleriyle Sinop Türkeli ilçesinden drene olan suyu toplayarak Karadeniz'e deşarj etmektedir [16, 17]. Akçay Havzası'nın en büyük ve ortalama yükseklikleri sırasıyla 2005 ve 1150 m'dir. Havzanın drenaj alanı $372.4 \mathrm{~km}^{2}$, çevresi $112.4 \mathrm{~km}$, en uzun akım yolu $35.6 \mathrm{~km}$ ve ortalama eğimi \% 45'tir. Bölgede dik eğim nedeniyle meydana gelen ani taşkınlar tarım alanları ve alt yapıya önemli zararlar verebilmektedir. Havzada eğri numarasının dağılımı, hidrolojik zemin grupları ve arazi örtüsü/kullanımı göz önünde bulundurularak ABD Tarım Departmanı tarafından önerilen sınıflandırma esas alınarak belirlenmiştir. Çalışılan havzanın hidrolojik zemin grupları, büyük toprak gruplarına göre değerlendirildiğinde çoğunluğunun D grubunda yer aldığı belirlenmiştir [16, 17]. Buna göre havzanın ortalama eğri numarası 79.32 olarak hesaplanmıştır (Şekil 1).

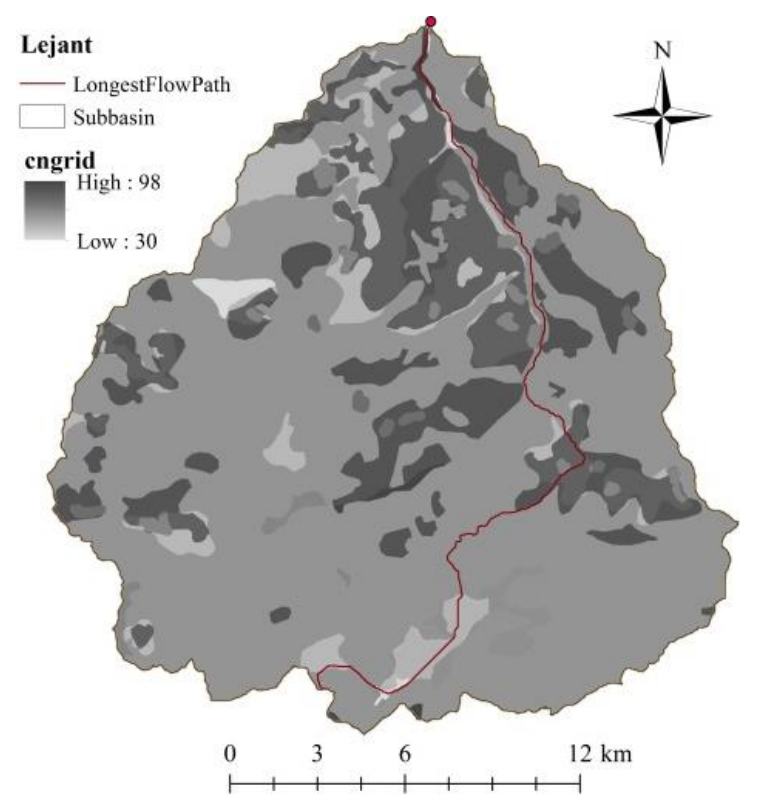

Şekil 1. Akçay Havzası'nın drenaj alanı, en uzun akım yolu ve eğri numarası değişimi. 


\subsection{Hidrolojik modelleme}

$\mathrm{Bu}$ çalışmada yağış-akış ilişkisini modellemek için yarı dağılımlı bir hidrolojik model olan Hydrologic Engineering Center-Hydrologic Modeling System (HEC-HMS) yazılımı kullanılmıştır. HEC-HMS hidrolojik modeli temel olarak alt havzalar için sızma, akış ve baz akım, akarsular için öteleme hidrolojik süreçlerini modeller [18]. Ayrıca, her bir alt havzaya ait yağış, buharlaşma, sıcaklık, nem, radyasyon gibi veriler de kullanılarak yazılım kapsamında meteorolojik modelleme de yapılabilir. Bu çalışmada Akçay Havzası tek havza olarak modellendiğinden sızma ve akış modelleri kullanılarak dolaysız akış hidrografı tahmin edilmiştir.

Havzanın çıkış noktasına yakın konumda bulunan Çatalzeytin MGİ'de Eylül 2008'de meydana gelen saatlik yağış verileri kullanılarak havzaya ait yağış modeli oluşturulmuştur. Havzanın sızma modeli SCS (Soil Conservation Service) sızma kaybı yöntemi kullanılarak modellenmiştir (Denklem 1 ve Denklem 2). Sızma kayıpları çıkarıldıktan sonra hesaplanan etkili yağıştan $\left(\mathrm{P}_{\mathrm{e}}\right)$ dolaysız akışa geçiş için Clark birim hidrografi yöntemi kullanılmıștır. Clark birim hidrografı yönteminde dolaysız akıș hidrografi, toplanma süresi $\left(\mathrm{T}_{\mathrm{c}}\right)$ ve depolama katsayılarına $\left(\mathrm{S}_{\mathrm{c}}\right)$ göre hesaplanabilmektedir. $\mathrm{T}_{\mathrm{c}}$ 'nin hesabı için literatürde farklı araştırmacılar tarafından önerilmiş farklı yaklaşımlar kullanılmaktadır. Bu çalışmada $\mathrm{T}_{\mathfrak{c}}, \mathrm{SCS}$ tarafından önerilen yöntem kullanılarak hesaplanmıştır (Denklem 3). $S_{c}$, arazi kullanımına göre değişebilen bir parametre olup literatürde genellikle $T_{c}$ ile ilişkilendirilerek ifade edilmiştir. Yoo ve diğerleri [5] çalıştıkları havzada yaptıkları kalibrasyon ve doğrulama sonuçlarına göre $\mathrm{S}_{\mathrm{c}}$ 'nin Denklem 4'te sunulduğu gibi hesaplanabileceğini ifade etmişlerdir.

$$
\begin{aligned}
& P_{e}=\frac{(P-0.2 S)^{2}}{P+0.8 S} \\
& S=\frac{25400}{C N}-254 \\
& T_{C}=\frac{4.111 L^{0.8}\left(\frac{1000}{C N}-9\right)^{0.7}}{1900 I^{0.5}} \\
& S_{C}=\frac{T_{C}}{1.46-0.0867 L^{2} / A}
\end{aligned}
$$

Yukarıdaki denklemlerde, S akış başladıktan sonra zeminin potansiyel nemini, CN eğri numarasını, L en uzun akım yolunu, I havzanın ortalama eğimini, A havzanın drenaj alanını ifade etmektedir. Hidrolojik analizde kullanılan $\mathrm{CN}, \mathrm{T}_{\mathrm{c}}$ ve $\mathrm{S}_{\mathrm{c}}$ parametrelerinin değerleri Tablo 1'de verilmiştir. Tablo 1'de belirlenen veriler kullanılarak dolaysız akış hidrograf hesaplanmıştır. Ayrıca hesaplanan pik debinin hidrolojik parametrelere duyarlılığının incelenmesi için Monte Carlo analizi uygulanmıştır.

Tablo 1. Hidrolojik analizde kullanılan parametreler

\begin{tabular}{|l|c|c|}
\hline $\mathbf{C N}$ & $\mathbf{T}_{\mathbf{c}}$ (saat) & $\mathbf{S}_{\mathbf{c}}$ (saat) \\
\hline 79.32 & 3.633 & 3.121 \\
\hline
\end{tabular}

\subsection{Monte Carlo analizi}

Akçay Havzası'nın sızma ve akış hidrolojik süreçlerinde kullanılan $\mathrm{CN}, \mathrm{T}_{\mathrm{c}}$ ve $\mathrm{S}_{\mathrm{c}}$ parametrelerinin değişiminin pik debi üzerindeki etkisi Monte Carlo yaklaşımı esasına göre incelenmiştir. Bu parametreler bazı dağılımlar dikkate alınarak istenilen sayıda Monte Carlo yaklaşımına göre rastgele üretilebilir. Jamshid-Mousavi ve diğerleri [11] ve Lehbab-Boukezzi ve diğerleri [13] parametrelerin üniform dağıldığını kabul ederek Monte Carlo yaklaşımına göre parametre değerlerini rastgele üretmiş ve hidrolojik analizleri yapmışlardır. Üniform dağılım, parametrelerin dağılımının bilinmemesi durumunda basit ve genel olarak kullanılabilecek bir istatistiksel yöntemdir. Bu çalışmada da üniform dağılımın yanı sıra normal ve üçgen dağılımlar da kullanılarak pik debiler hesaplanmış ve farklı dağılımların parametre duyarlılıkları üzerindeki etkisi incelenmiştir. Farklı dağılımların pik debi üzerinde duyarlılığını kıyaslayabilmek için hidrolojik parametrelerin Tablo 1 'deki değerleri ile aynı değişim katsayısı (COV) dikkate alınarak rastgele değerleri üretilmiş (Tablo 2) ve pik debiler hesaplanmıştır. Rastgele üretilen parametre sayısı arttıkça hesaplanan pik debilerin güven aralığı daralacağından ve COV değerleri de azalacağından parametre sayısı 10000 olarak seçilmiştir. Tablo 1'de hesaplanan parametre değerleri istatistiksel dağılıma göre ortalama veya mod değerler olarak alınmıştır. COV değerleri parametrelerin 
rastgele üretilmesinde ve dağllımlarda kullanılan standart sapma, minimum ve maksimum değerlerinin hesaplanabilmesi için kullanılmıştır. Bu çalışmada COV değeri \%2.9 alınarak $\mathrm{T}_{\mathrm{c}}$ ve $\mathrm{S}_{\mathrm{c}}$ 'nin değişimi sınırlanmış ve CN'nin de zeminin farklı nem durumlarına bağlı olarak modellenebilmesi sağlanmıştır. Üretilen değerler HEC-HMS hidrolojik modeli yardımıyla hesaplanan dolaysız akış hidrograflarının ve pik debi değerlerinin belirlenmesinde kullanılmıştır. Pik debilerin eşit değişim katsayısından ve istatistiksel dağılımdan nasıl etkilendikleri duyarlılık analizi yapılarak incelenmiştir. Her bir analizde hesaplanan 10000 pik debiye göre $\% 95$ güven aralığının alt ve üst sınırları belirlenmiş ve Tablo 1'deki değerlerle hesaplanan pik debinin bu güven aralığında kalıp kalmadığı incelenmiştir.

Tablo 2. Monte Carlo Analizinde kullanılan parametrelerin istatistiksel özellikleri

\begin{tabular}{|l|l|l|l|}
\hline Analiz No & Parametre & COV (\%) & Dağglım \\
\hline 1 & $\mathrm{~T}_{\mathrm{c}}$ & 2.9 & Üniform \\
\hline 2 & $\mathrm{~S}_{\mathrm{c}}$ & 2.9 & Üniform \\
\hline 3 & $\mathrm{CN}$ & 2.9 & Üniform \\
\hline 4 & $\mathrm{~T}_{\mathrm{c}}$ & 2.9 & Normal \\
\hline 5 & $\mathrm{~S}_{\mathrm{c}}$ & 2.9 & Normal \\
\hline 6 & $\mathrm{CN}$ & 2.9 & Normal \\
\hline 7 & $\mathrm{~T}_{\mathrm{c}}$ & 2.9 & Üçgen \\
\hline 8 & $\mathrm{~S}_{\mathrm{c}}$ & 2.9 & Üçgen \\
\hline 9 & $\mathrm{CN}$ & 2.9 & Üçgen \\
\hline
\end{tabular}

\subsection{Duyarlılık analizi}

$\mathrm{Bu}$ çalışma kapsamında her analizde parametrelerin pik debi üzerindeki etkisi lokal duyarlılık analizi yapılarak irdelenmiştir. Lokal duyarlılık analizi, uygulanması kolay olduğundan tercih edilmiştir. Parametrelerin pik debi üzerindeki bağıl duyarlılığı $\left(\mathrm{S}_{\mathrm{r}}\right)$ Denklem 5 ile hesaplanmıştır [19].

$S_{r}=\frac{O_{2}-O_{1}}{V_{2}-V_{1}} \frac{V_{2}+V_{1}}{O_{2}+O_{1}}$

burada $\mathrm{O}$ ve $\mathrm{V}$ sırasıyla pik debiyi ve değiştirilen parametreyi ifade etmektedir. $\mathrm{S}_{\mathrm{r}}$ değeri boyutsuz bir büyüklük olduğundan ve parametreler arası karşılaştırma yapılabilmesine olanak sağladığı için tercih edilmiştir [20]. $S_{\mathrm{r}}$ değerinin göreceli olarak büyük olması, o hidrolojik parametrenin pik debi üzerinde duyarlılığının fazla olduğunu göstermektedir.

\section{Bulgular ve Tartıșma}

Tablo 1'de hesaplanan parametreler ve Eylül 2008'de meydana gelen saatlik yağış verileri HEC-HMS yarı dağılımlı hidrolojik modelde kullanılarak hesaplanan dolaysız akış hidrografi Şekil 2'de verilmiştir. Bu yağış sonucunda pik debi $323.27 \mathrm{~m}^{3} / \mathrm{sn}$ olarak hesaplanmıștır. Şekil 3'te analiz 1 durumunda minimum, ortalama, maksimum ile ortalamanın bir standart sapma fazlası ve eksiği dikkate alınarak model tarafından hesaplanmış dolaysız akış hidrograf örneği sunulmuştur. Tablo 2'de verilen analiz senaryolarına göre Monte Carlo yaklaşımıyla üretilen parametrelerin en küçük ve en büyük değerleri Tablo 3'te verilmiştir. Ayrıca Tablo 3'te Tablo 2'de verilen durumlarda üretilen rastgele parametrelerle hesaplanan pik debilerin \%95 güven aralığına göre en büyük (\%95 UL) ve en küçük değerleri (\%95 LL), hesaplanan pik debilerin COV değerleri ile parametrelerin hesaplanan pik debiler üzerindeki $S_{r}$ bağıl duyarlılıkları sunulmuştur. Monte Carlo yaklaşımıyla üretilen hidrolojik parametrelerin en büyük ve en küçük değerleri arasındaki açıklık en büyükten en küçüğe doğru sıralaması sırasıyla normal, üçgen ve üniform dağılımlarında gerçekleşmiştir. Tablo 1'de verilen parametrelerle yapılan hidrolojik modelle hesaplanan pik debi (Şekil 2), kullanılan istatistiksel dağılımdan bağımsız olarak üretilen $T_{c}$ parametresiyle hesaplanan pik debilere göre \%95 güven aralığında yer almamaktadır. Aksine, Şekil 2'de hesaplanan pik debi kullanılan istatistiksel dağılımdan bağımsız olarak üretilen CN parametresiyle hesaplanan pik debilere göre de \%95 güven aralığında yer almaktadır. Sadece normal dağılım dikkate alınarak üretilen $\mathrm{S}_{\mathrm{c}}$ parametresi ile hesaplanan pik debi \%95 güven aralığında yer almamaktadır. Monte Carlo analizi ve hidrolojik modelleme sonuçlarına göre hesaplanan pik debilerin COV değerleri, kabul edilen istatistiksel dağılımdan bağımsız olarak en küçükten en büyüğe doğru parametreler sırasıyla $T_{c}, S_{c}$ ve $C N$ 'dir. 
Tüm istatistiksel dağılımlara göre CN parametresi için hesaplanan COV değeri diğer parametrelere kıyasla oldukça fazla olduğundan tüm istatistiksel dağılımlarda \% 95 güven aralığı oldukça geniş bantta meydana gelmiştir. $\mathrm{T}_{\mathrm{c}}$ parametresi için de bu durumun tam tersi söz konusudur. Hidrolojik parametrelerin pik debi üzerindeki duyarlılığg $\left(\mathrm{S}_{\mathrm{r}}\right)$, kullanılan istatistiksel dağılımdan bağımsız olarak incelendiğinde en küçük bağıll duyarlılığa sahip olan parametre $T_{c}$ ve en büyük bağıl duyarlılığa sahip parametre $C N$ 'dir. Elde edilen sonuçlar bu yönüyle $\mathrm{COV}$ ve $\mathrm{S}_{\mathrm{r}}$ değerlerinin arasında bir uyum olduğunu göstermektedir. Etkili yağıştan akışa dönüşüm parametrelerinden $S_{c}$ 'nin $T_{c}$ 'ye kıyasla pik debi üzerinde daha etkili olduğu görülmüştür.

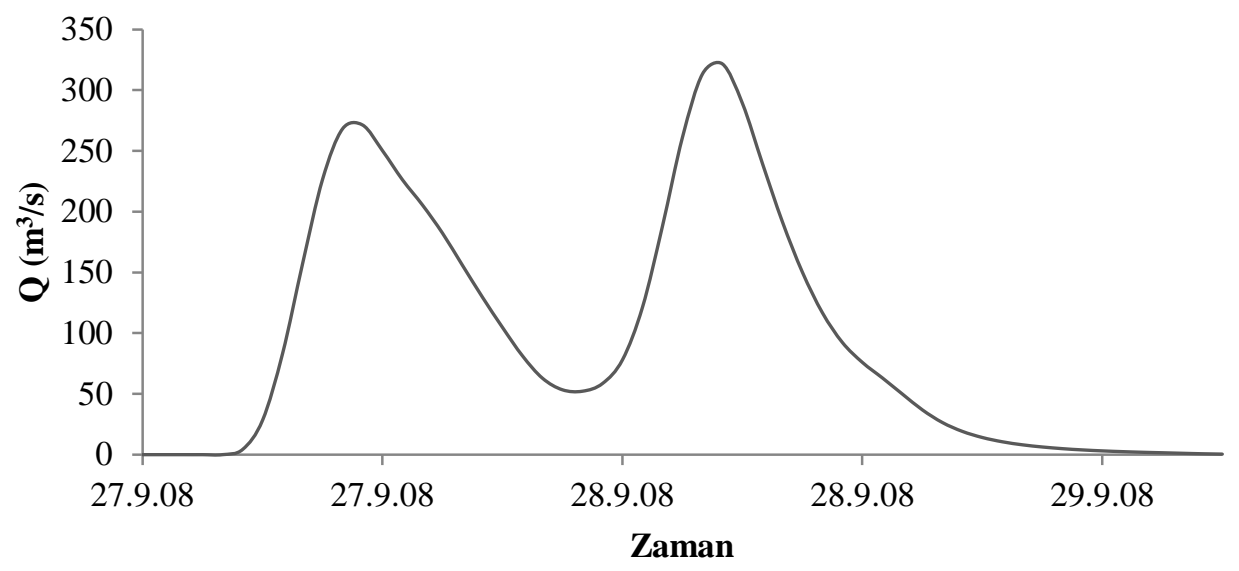

Şekil 2. Parametrelere göre hesaplanan dolaysız akış hidrografi.

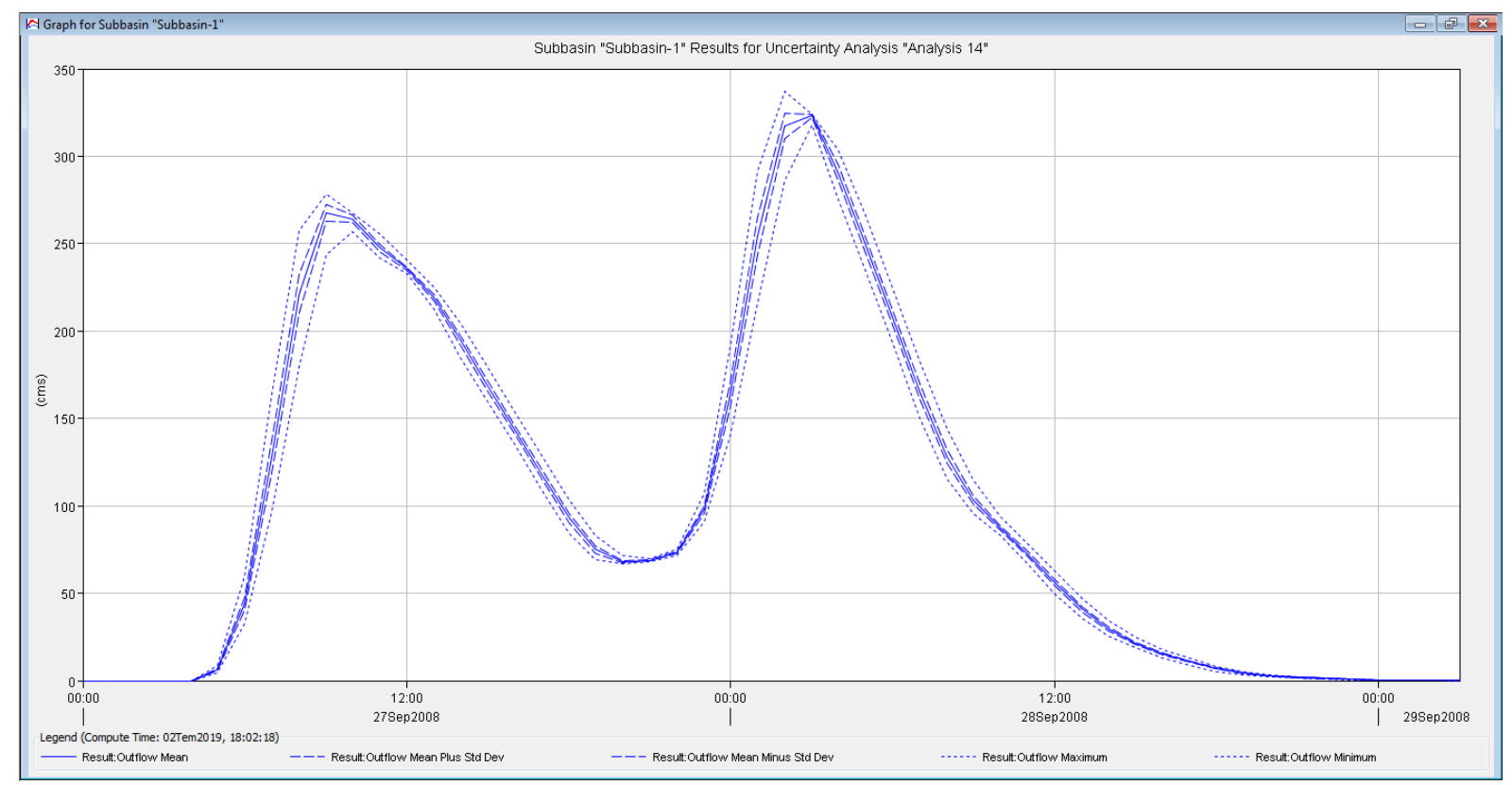

Şekil 3. Analiz 1 için model tarafından hesaplanan minimum, ortalama, maksimum ile ortalamanın bir standart sapma eksiği ve fazlası dolaysız akış hidrografı. 
Tablo 3. Monte Carlo Analizinde kullanılan parametreler ve hesaplanan pik debilerin istatistiksel özellikleri

\begin{tabular}{|c|c|c|c|l|l|l|l|}
\hline Analiz No & Parametre & En küçük değer & En büyük değer & \%95 LL & \%95 UL & COV (\%) & Sr \\
\hline 1 & $\mathrm{~T}_{\mathrm{c}}$ & 3.451 & 3.815 & 323.28 & 323.29 & 0.09 & 0.03 \\
\hline 2 & $\mathrm{~S}_{\mathrm{c}}$ & 2.965 & 3.277 & 323.26 & 323.39 & 0.99 & 0.35 \\
\hline 3 & $\mathrm{CN}$ & 75.35 & 83.29 & 322.70 & 323.36 & 5.28 & 1.82 \\
\hline 4 & $\mathrm{~T}_{\mathrm{c}}$ & 3.260 & 4.006 & 323.36 & 323.38 & 0.16 & 0.11 \\
\hline 5 & $\mathrm{~S}_{\mathrm{c}}$ & 2.808 & 3.449 & 323.30 & 323.43 & 0.98 & 0.34 \\
\hline 6 & $\mathrm{CN}$ & 71.11 & 87.71 & 323.09 & 323.80 & 5.60 & 2.57 \\
\hline 7 & $\mathrm{~T}_{\mathrm{c}}$ & 3.380 & 3.886 & 323.34 & 323.36 & 0.12 & 0.08 \\
\hline 8 & $\mathrm{~S}_{\mathrm{c}}$ & 2.903 & 3.334 & 323.26 & 323.38 & 0.98 & 0.34 \\
\hline 9 & $\mathrm{CN}$ & 73.86 & 84.87 & 322.68 & 323.36 & 5.37 & 2.19 \\
\hline
\end{tabular}

\section{Sonuçlar}

Batı Karadeniz Havzası'nda yer alan Akçay Havzası'nın Eylül 2008'de meydana gelen saatlik yağış verileri kullanılarak HEC-HMS programı yardımıyla hidrolojik modelleme yapılmıştır. ArcGIS ve HECGeo-HMS yazılımları kullanılarak havza modeli oluşturulmuştur. Sızma ve dolaysız akış süreçlerinin hesaplanabilmesi için sırasıyla SCS ve Clark birim hidrograf yöntemi kullanılmıștır. Havzanın eğri numarası, zemin tipi ve arazi kullanım haritasına göre belirlenmiş olup hem sızma modelinde hem de toplanma süresinin hesaplanmasında kullanılmıştır. Clark birim hidrograf yönteminde akışın hesaplanması için kullanılan depolama katsayısı Yoo ve diğerleri [5] tarafından önerilen yaklaşıma göre hesaplanmıştır. Belirlenen parametreler modellemede kullanılmış ve dolaysız akış hidrografi hesaplanmıştır.

ArcGIS ve HECGeo-HMS olanaklarıyla tahmin edilen parametreler belirsizlik içerdiğinden zamandan bağımsız hidrolik analizlerde de kullanılabilecek pik debinin parametre değişimlerine duyarlılığı incelenmiştir. HEC-HMS yardımıyla hidrolojik parametreler ayrı ayrı üniform, normal ve üçgen dağılımlar dikkate alınarak ve eşit değişim katsayısına sahip olacak şekilde Monte Carlo yaklaşımıla rastgele 10000 adet üretilmiştir. Bu parametreler kullanılarak hidrolojik süreçler modellenmiş, dolaysız akış hidrografı ve pik debilerin değişim aralığı hesaplanmıştır. ArcGIS ve HECGeo-HMS olanaklarıyla tahmin edilen hidrolojik parametrelerle hesaplanan pik debilerin güven aralığının alt ve üst limitleri belirlenmiştir. Monte Carlo yaklaşımında kullanılan istatistiksel dağılımdan bağımsız olmak üzere eğri numarasının pik debi üzerinde en fazla, toplanma süresinin de en az duyarlılığa sahip olduğu görülmüştür. Bu çalışma kapsamında yapılan duyarlılık analizi sonuçlarına göre hidrolojik süreçlerin modellenmesinde kullanılan parametrelerin tahmininde meydana gelebilecek sapmaların elde edilecek sonucu ne ölçüde etkileyebildiği görülmüştür. Ayrıca, bilinen yağış-akış verilerine göre hidrolojik parametrelerin kalibrasyonunda duyarlık analizi sonuçları kullanılarak amaç fonksiyonuna daha az işlemle erişim sağlanabilir.

\section{Teșekkür}

Yazar, bu çalı̧̧manın gerçekleştirilmesinde 114M292 no'lu projeye destek verdiği için TÜBİTAK'a teşekkürlerini sunmaktadır.

\section{Kaynaklar}

[1] Sivapalan M, Takeuchi K, Franks SW, Gupta VK, Karambiri H, Lakshmi V, Liang X, McDonnell JJ ve diğgerleri. IAHS decade on predictions in ungauged basins (PUB), 2003-2012: Shaping an exciting future for the hydrological sciences. Hydrolog Sci J 2003; 48(6):857-880.

[2] Yadav M, Wagener T, Gupta H. Regionalization of constraints on expected watershed response behavior for improved predictions in ungauged basins. Adv Water Resour 2007; 30(2007):1756-1774.

[3] Khan SI, Hong Y, Wang J, Yilmaz KK, Gourley JJ, Adler RF, Brakenridge GR, Policelli F ve diğerleri. Satellite remote sensing and hydrologic modeling for flood inundation mapping in Lake Victoria Basin: implications for hydrologic prediction in ungauged basin. IEEE T Geosci Remote 2011; 49(1):85-95.

[4] Piman T, Babel MS. Prediction of rainfall-runoff in an ungauged basin: case study in the mountainous region of Northern Thailand. J Hydrol Eng 2013; 18(2):285-296.

[5] Yoo C, Lee J, Park C, Jun C. Method for estimating concentration time and storage coefficient of the Clark model using rainfall-runoff measurements. J Hydrol Eng 2014; 19(3):626-634. 
[6] Baduna Koçyiğit M, Akay H, Yanmaz AM. Effect of watershed partitioning on hydrologic parameters and estimation of hydrograph of an ungauged basin: a case study in Gokirmak and Kocanaz, Turkey. Arab J Geosci 2017; 10(15):331.

[7] Akay H, Baduna Koçyiğit M, Yanmaz AM. Effect of using multiple stream gauging stations on calibration of hydrologic parameters and estimation of hydrograph of ungauged neighboring basin. Arab J Geosci 2018; 11(11):282.

[8] Abbaspour KC, Vaghefi SA, Srinivasan R. A guideline for successful calibration and uncertainty analysis for soil and water assessment: a review of papers from the 2016 international SWAT conference. Water 2018; 10(1):6.

[9] Rafiei Emam A, Kappas M, Fassnacht S, Linh NHK. Uncertainty analysis of hydrological modeling in a tropic area using different algorithms. Front Earth Sci-PRC 2018; 12(4):661-671.

[10] Shamsudin S, Dan'azumi S, Ab Rahman A. Uncertainty Analysis of HEC-HMS Model Parameters Using Monte Carlo Simulation. International Journal of Modelling and Simulation 2011; 31(4):279-286.

[11] Jamshid Mousavi S, Abbaspour KC, Kamali B, Amini M, Yang H. Uncertainty-based automatic calibration of HECHMS model using sequential uncertainty fitting approach. J Hydroinform 2012; 14(2):286-309.

[12] Yang SC, Yang TH. Uncertainty assessment: reservoir inflow forecasting with ensemble precipitation forecasts and HEC-HMS. Adv Meteorol 2014; 2014:581756.

[13] Lehbab-Boukezzi Z, Boukezzi L, Errih M. Uncertainty analysis of HEC-HMS model using the GLUE method for flash flood forecasting of Mekerra watershed, Algeria. Arab J Geosci 2016; 9(20):751.

[14] Linhoss A, Munoz-Carpena R, Kiker G, Hughes D. Hydrologic Modeling, Uncertainty, and Sensitivity in the Okavango Basin: Insights for Scenario Assessment. J Hydrol Eng 2013; 18(12):1767-1778.

[15] Yanmaz AM. Applied Water Resources Engineering. Ankara, Turkey: Metu Press, 2013.

[16] Akay H, Baduna Koçyiğit M. Ölçüm alınmayan bir havzada yağış akış ilişkisinin bir hidrolojik model yardımıyla belirlenmesi: Akçay Havzası örneği. In: 3rd International Congress on Technical and Vocational Sciences; June 2018; Gaziantep, Turkey. pp.2154-2159.

[17] Baduna Koçyiğit M, Akay H. Estimation of potential flash flood risk in a basin using morphometric parameters: A case study of Akçay Basin. J Fac Eng Archit Gaz 2018; 33(4):1321-1332.

[18] US Army Corps of Engineers Hydrologic Engineering Center (USACE). Hydrologic modeling system HEC-HMS user's manual. USA: USACE, 2013.

[19] Haan CT. Uncertainty analysis of hydrologic and water quality models. Lecture notes, 1996.

[20] Kumar R, Chatterjee C, Lohani AK, Kumar S, Singh RD. Sensitivity analysis of the GIUH based Clark model for a catchment. Water Resour Manag 2002; 16(4):263-278. 